\title{
- Let's Enjoy Civilized Life Using Limited Amount of Fossil Fuel
}

Volume 6 Issue 3 - 2017

\author{
Keywords: Fossil fuel, NOx, Civilized life, $\mathrm{Co}_{2}$ assimilation \\ Opinion
}

Oil is fossil of plankton and coal is a fossil of tree made by $\mathrm{CO}_{2}$ assimilation from $\mathrm{CO}_{2}$ and water in 50 billion years. Mankind is now using up this fossil fuel in 500 years. Estimated amount of buried fossil fuel: oil is 42 years, natural gas is 60 years, coal is 132 years. It is said that oil production reaches maximum in 2037(earlier in 2026, latest in 2047) and decrease quickly. When fossil is burned out. How can we live civilized life. How can we drive car, air plane, agriculture machine, fishing boat. How can we generate electricity. From what can we make plastic and solar cell module. Fossil fuel is limited very very precious treasure for our mankind. We must consider how to use the limited precious fossil fuel.

We must consider most useful method to use limited amount of fossil fuel. Fossil fuel $1.4 \times 10^{10}$ tones was burned at whole world in 2015 and about $4.4 \times 10^{10}$ tone $\mathrm{CO}_{2}$ and $7.4 \times 10^{15} \mathrm{kcal}$ were produced and $2.5 \times 10^{9}$ tone NOx is produced. If we use this $2.5 \times 10^{9}$ tone NOx for $\mathrm{CO}_{2}$ assimilation, we can fix $\mathrm{CO}_{2} 50 \times 10^{9}$ tone $\left(25 \times 2.5 \times 10^{9}\right)$. Some country is eliminating NOx by ammonia. To eliminate NOx $2.5 \times 10^{9}$ tone, equimolar ammonia 11.3 billion ton is used. To make ammonia 11.3 billion tone, 2 billion tone hydrogen gas ie used. To make 2 billion tone hydrogen, butane 6.4 billion tone is used. As the result, 17.6 billion tone $\mathrm{CO}_{2}$ is released. This elimination is not clever way. If NOx elimination is stopped, 17.6 billion tone $\mathrm{CO}_{2}$ release can be stopped. And 17.6x 25=440 billion tone $\mathrm{CO}_{2}$ can be fixed.

Promotion of wood production. There is 800 billon tone wood in the world and increasing 1-2\% annually. Tree grows quickly by the promotion of $\mathrm{CO}_{2}$ assimilation. Big trees are glowing at West Mountain at west Canada and United State supported by Salmon which swim up the river and eaten by bear and provide nutrient nitrogen. The salmon grow by eating plankton at nutrient rich sea. Promotion of plankton promotes fish production and promotes wood growth. This wood might be a candidate of oil substitute.

\author{
Shoichiro Ozaki \\ Professor emeritus Ehime University, Japan
}

Correspondence: Shoichiro Ozaki, Professor emeritus Ehime University, Japan, Email ozaki-0991@jcom.zaq.ne.jp

Received: September 19, 2017 | Published: September 20, 2017

Fuel efficiency of car decrease when NOx generation is restricted. Too strict law to diminish NOx causes heavy loss of fuels.

NOx is biggest fertilizer and NOx is playing very important role for the growth of plant, production of corn, fish NOx elimination consume huge fuel and generate huge $\mathrm{CO}_{2}$ and promote global warming. Therefore NOx elimination at power station should be stopped.

\section{Acknowledgements}

None.

\section{Conflicts of interest}

None. 